\title{
Assessment of Knowledge of Breast Cancer Risk Factors and Practice of Breast Self Examination among Paramedical Females
}

\author{
Fauzia Khan ${ }^{1}$, Navreet Boora ${ }^{2}$, Raushan Kumar ${ }^{3}$, Niraj Kumar Sah $^{4}$ \\ ${ }^{1}$ M.Sc. (RIT) Research Fellow, Radiological Imaging Techniques, TMU, Moradabad, Uttar Pradesh, India \\ ${ }^{2,3,4}$ Assistant Professor, Radiological Imaging Techniques, Faculty of College of Paramedical Science, TMU, \\ Moradabad, Uttar Pradesh, India \\ Corresponding Author: Fauzia Khan
}

\begin{abstract}
Objectives: The aim of the this research was therefore to explore the scale of mammary gland malignancy knowledge among students in paramedical college, looking on awareness of mammary gland malignancy warning symptoms, risk factors, detection strategy and breast self-assessment.
\end{abstract}

Methods: A questionnaire based Cross sectional study was carried out in college of paramedical sciences. This study was questionnaire based on Assessment of knowledge of breast cancer risk factors and practice of BSE among paramedical females

Result: Out of 250 female, 207 were available for final analysis. In this study assess the knowledge of female faculty and students about Breast cancer, risk factors and practice of Breast Self Examination and calculated the mean value of respondents who give the correct answer and concluded that the knowledge of female faculty have average $63.08 \%$, Radiology and Imaging Techniques students had good knowledge $63.6 \%$, Optometry students had average knowledge $61.88 \%$, Bachelor of Medical Laboratory Techniques had insufficient knowledge $49.63 \%$ and Bachelor of Forensic Sciences were average knowledge $65.8 \%$.The result of this study was not satisfied, knowledge of respondents were not enough for this serious and most common cancer of women

Conclusion: Study concluded that there should be proper lectures and theory classes for the conduction of knowledge about Breast cancer, risk factors and BSE in paramedical college, This questionnaire based survey demonstrate that up-to-date practice of breast self examination among paramedical females were not sufficient, this should be improved by the well designed training and theoretical sessions. From this study, we suggest that all members of the health care community should attend the webinars, guest lectures and training sessions about knowledge of breast cancer, risk factor and practice of breast self-examination.

Keywords: Breast cancer, BSE, Risk factors

\section{INTRODUCTION}

BREAST CANCER-Mammary gland malignancy is the most regular invasive malignancy of female and lung malignancy is first most usual cancer, the $2^{\text {nd }}$ main source of malignancy mortality in female is breast cancer. Mammary gland malignancy is the most widely recognized pathology analyzed in females, after skin disease in the US. Both men and women can affect by breast cancer, but it's far more frequent in women. Breast cancer is the highest persistent malignancy of women universal, according to WHO per year over 1.4 million female universal are determined have mammary gland malignant growth as it represents for $23 \%$ of freshly identified malignancy. In Indian women mammary gland $t$ cancer accounts for $14 \%$. It is reported that, an Indian female is investigated have mammary gland malignancy with every 4 minutes. Both in rural and urban Indian, breast cancer is on 
Fauzia Khan et.al. Assessment of knowledge of breast cancer risk factors and practice of breast self examination among paramedical females.

the rise. A 2018 report of mammary gland malignancy figures recorded $1,162,468$ freshly enlisted patient and 87,090 detailed rate of mortality. Vitality of cancer get most severe in elevated level of its advancement .Stage 3 and 4 of breast cancer accounts more than $50 \%$ of Indian women. Due to deficiency of knowledge and worst prior screening and determination rates, are causes of low mammary gland malignancy vitality rate in Indian women .As the most ordinary tumor type in women of India. Women in their prior $30 \mathrm{~s}$ to $50 \mathrm{~s}$ are at noticeable danger to create mammary gland malignancy, and the occurrence hazard increment till its climax when they arrive at long term old enough. Due to late detection, in India the vitality rate of mammary gland malignancy are low. To change these numbers increasing awareness is the only way. Breast cancer is a treatable disease and if it is diagnosed within time, probability of survival is higher. ${ }^{[1]}$

\section{Breast self examination:}

Breast self examination is analysis of breast to look for changes or problems in the breast tissue done by woman at home. About 3to5 days after your period starts, is the actual time to perform a monthly BSE. Every month do it at the same time. At this time in your monthly cycle, your breasts are not as tender or lumpy. ${ }^{[3]}$

\section{Steps to a Better Breast Self-exam in females}

- Step 1: Go ahead by focusing for dissimilarities between your breast

- Step 2: Place your hands on your hips, drag your elbows ahead.

- Step 3: When inspecting your breasts use three fingers.

- Step 4: Inspecting the region nearby the breast.

- Step 5: Do the exam at the same time each month. ${ }^{[2]}$

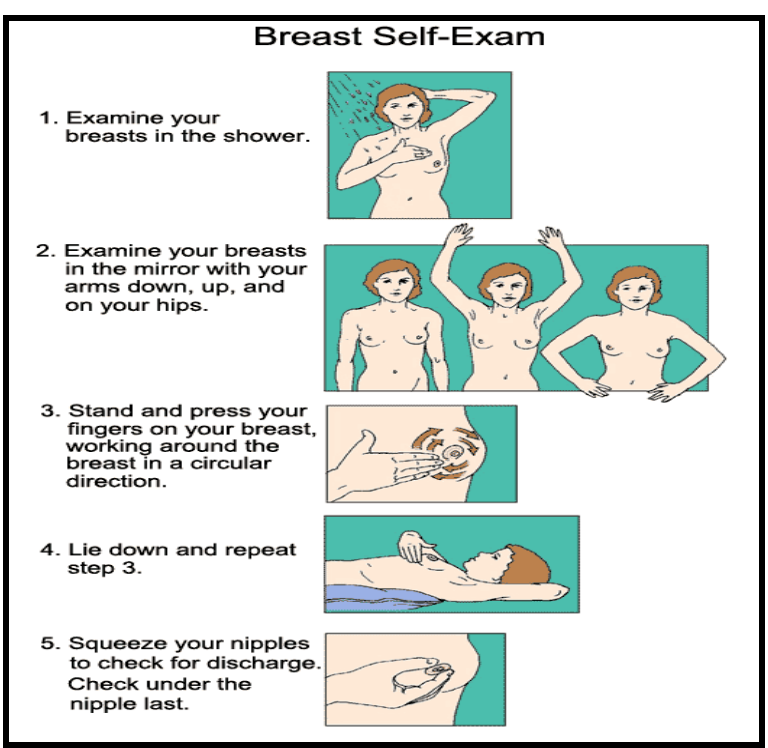

Fig. 1: Shows Steps of Breast Examination ${ }^{[2]}$

\section{METHOD AND MATERIAL}

STUDY TYPE: A questionnaire based Cross sectional study was carried out in college of paramedical sciences at Teerthanker Mahaveer University, Delhi road Moradabad, Uttar Pradesh, India. This study was questionnaire based on Assessment of knowledge of breast cancer risk factors and practice of BSE among paramedical females.

STUDY DESIGN: This study was prospective \& questionnaire based designed and carried out among paramedical students of College of Paramedical Sciences at Teerthanker Mahaveer University Delhi road Moradabad. Knowledge about Breast cancer, Risk factors and BSE of postgraduate, undergraduate students, from four departments' i.e. radiological imaging techniques, medical lab techniques and optometry, Forensic science. The project was approved by the college review committee.

STUDY AREA: Faculties, Students pursuing bachelors \& masters degree in College of paramedical sciences Teerthanker Mahaveer University.

\section{STUDY DURATION}

This questionnaire based study carried out for the time period of one year from 1 March 2020 to 1 March 2021 at College of Paramedical Sciences TMU Delhi road Moradabad Uttar Pradesh, India. 


\section{SELECTION CRITERIA}

- Inclusion criteria students of paramedical college.

- Radiology students

- Laboratory students

- Optometry students

- Forensic students

- Faculty

- Exclusion criteria

- Diploma students were excluded

- Non medical students were excluded

- That student who not acknowledged taking interest in the study.

STUDY POPULATION: The size of the population was 250 students. The study population consisted of students and faculty including female of four department i.e. radiological imaging techniques, medical lab techniques, optometry and forensic sciences of paramedical science excluding the candidates who fell under exclusion criteria.

\section{METHOD OF DATA COLLECTION:}

The study was carried out among students of four department of paramedical science i.e. radiological imaging techniques, medical lab techniques and optometry, Forensic sciences excluding the candidates who fell under exclusion criteria and who were willing to participate were included in the research. The aim of the research was explained to each and every individual. After assessing these criteria, a total number of 207 participants werel]included in the study. Verbal form was acquired from all respondents included in this research. The questionnaire was structured by using Google form \& was distributed in different WhatsApp groups via internet. The inquiries were joined subsequent to going through different writing identified with that, which comprised of self structured questionnaire divided into two sections. the first section of questionnaire consisted of demographic data including name ,age, program, department, the second section of questionnaire consisted of 24 basic questions regarding assessing adequate knowledge of the participant to Breast cancer and BSE.
STATISTICAL ANALYSIS: The data collected was compiled, arranged and analyzed. Analysis was done using Google form.

\section{RESULT}

Out of 250 female, 207 were available for final analysis. In. 207 respondent, $43 \%(9)$ were female faculties of paramedical department $7.7 \%(16)$ were female students of Masters of Radiology and Imaging Techniques, $1.4 \%(3)$ were Masters of Optometry, 30\%(62) were female students of Bachelor of Radiology and Imaging techniques, 21.3\%(44) were female students of Bachelor of Medical Laboratory Techniques, 27\%(56) were female students of Bachelor of Optometry, $10.2 \%$ (21) were female students of Bachelor of Forensic Sciences.

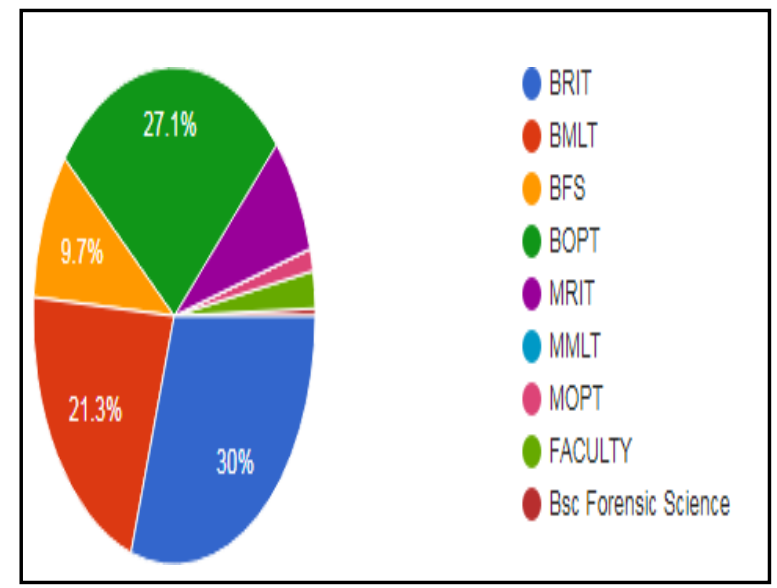

Pie chart shows the percentage of total number of respondents according to course

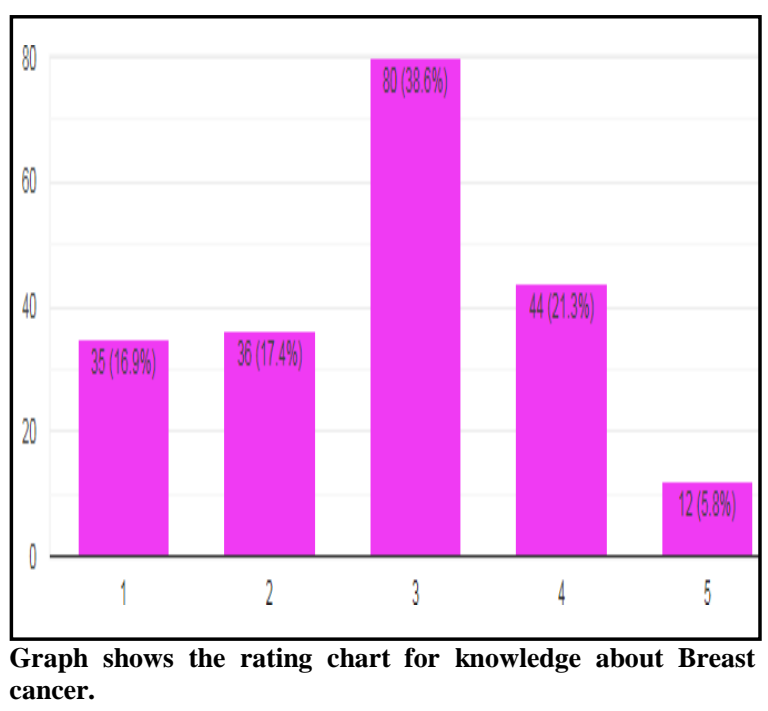


Fauzia Khan et.al. Assessment of knowledge of breast cancer risk factors and practice of breast self examination among paramedical females.

\begin{tabular}{|c|c|c|c|r|r|r|}
\hline Q. & FACULTY & \multicolumn{1}{|c|}{ RIT76 } & OPT58 & BMLT44 & \multicolumn{1}{c|}{ BFS20 } & OverallPercentage(207) \\
\hline Q1 & $88.88 \%$ & $85.40 \%$ & $83.63 \%$ & $67.27 \%$ & $85 \%$ & $86.00 \%$ \\
\hline Q2 & $100 \%$ & $95.08 \%$ & $89.09 \%$ & $78.18 \%$ & $100 \%$ & $95.65 \%$ \\
\hline Q3 & $88.88 \%$ & $52.40 \%$ & $69.09 \%$ & $50.90 \%$ & $60 \%$ & $64.70 \%$ \\
\hline Q4 & $66.66 \%$ & $65.57 \%$ & $49.09 \%$ & $36.36 \%$ & $40 \%$ & $56.00 \%$ \\
\hline Q5 & $77.77 \%$ & $78.68 \%$ & $72.72 \%$ & $52.72 \%$ & $75 \%$ & $75.80 \%$ \\
\hline Q6 & $100 \%$ & $95.08 \%$ & $90.09 \%$ & $76.36 \%$ & $100 \%$ & $93.60 \%$ \\
\hline Q7 & $44.44 \%$ & $24.59 \%$ & $41.81 \%$ & $41.81 \%$ & $70 \%$ & $41.40 \%$ \\
\hline Q8 & $100 \%$ & $80.32 \%$ & $76.36 \%$ & $63.64 \%$ & $100 \%$ & $83.60 \%$ \\
\hline Q9 & $44.44 \%$ & $22.95 \%$ & $21.81 \%$ & $20.00 \%$ & $35 \%$ & $51.70 \%$ \\
\hline Q10 & $66.66 \%$ & $44.26 \%$ & $63.63 \%$ & $29.09 \%$ & $50 \%$ & $43.50 \%$ \\
\hline Q11 & $55.55 \%$ & $42.62 \%$ & $32.77 \%$ & $36.36 \%$ & $40 \%$ & $50.70 \%$ \\
\hline Q12 & $55.55 \%$ & $36.06 \%$ & $56.36 \%$ & $34.54 \%$ & $65 \%$ & $46.90 \%$ \\
\hline Q13 & $44.44 \%$ & $59.01 \%$ & $40 \%$ & $29.09 \%$ & $40 \%$ & $71.00 \%$ \\
\hline Q14 & $66.66 \%$ & $78.68 \%$ & $61.81 \%$ & $56.36 \%$ & $70 \%$ & $50.20 \%$ \\
\hline Q15 & $55.55 \%$ & $22.95 \%$ & $34.54 \%$ & $20 \%$ & $25 \%$ & $81.6 \%$ \\
\hline Q16 & $55.55 \%$ & $85.24 \%$ & $76.36 \%$ & $70.90 \%$ & $90 \%$ & $75.40 \%$ \\
\hline Q17 & $66.66 \%$ & $70.49 \%$ & $81.81 \%$ & $58.18 \%$ & $75 \%$ & $38.20 \%$ \\
\hline Q18 & $22.22 \%$ & $32.70 \%$ & $41.81 \%$ & $43.63 \%$ & $15 \%$ & $72.00 \%$ \\
\hline Q19 & $55.55 \%$ & $81.96 \%$ & $67.27 \%$ & $60 \%$ & $55 \%$ & $88.90 \%$ \\
\hline Q20 & $77.77 \%$ & $80.32 \%$ & $90.90 \%$ & $72.72 \%$ & $95 \%$ & $90.33 \%$ \\
\hline Q21 & $100 \%$ & $93.44 \%$ & $81.81 \%$ & $72.72 \%$ & $95 \%$ & $71.50 \%$ \\
\hline Q22 & $100 \%$ & $68.85 \%$ & $69.09 \%$ & $40 \%$ & $85 \%$ & $54.60 \%$ \\
\hline Q23 & $44.44 \%$ & $75.40 \%$ & $32.72 \%$ & $32.72 \%$ & $50 \%$ & \\
\hline
\end{tabular}

Table shows total percentage of right answer observed from different respondent categories (Percentage of correct answer out of 207) knowledge of female faculty have average $63.08 \%$, Radiology and Imaging Techniques students had good knowledge $63.6 \%$, Optometry students had average knowledge $61.88 \%$, Bachelor of Medical
Laboratory Techniques had insufficient knowledge $49.63 \%$ and Bachelor of Forensic Sciences were average knowledge $65.8 \%$. The result of this study was not satisfied, knowledge of respondents were not enough for this serious and most common cancer of women.

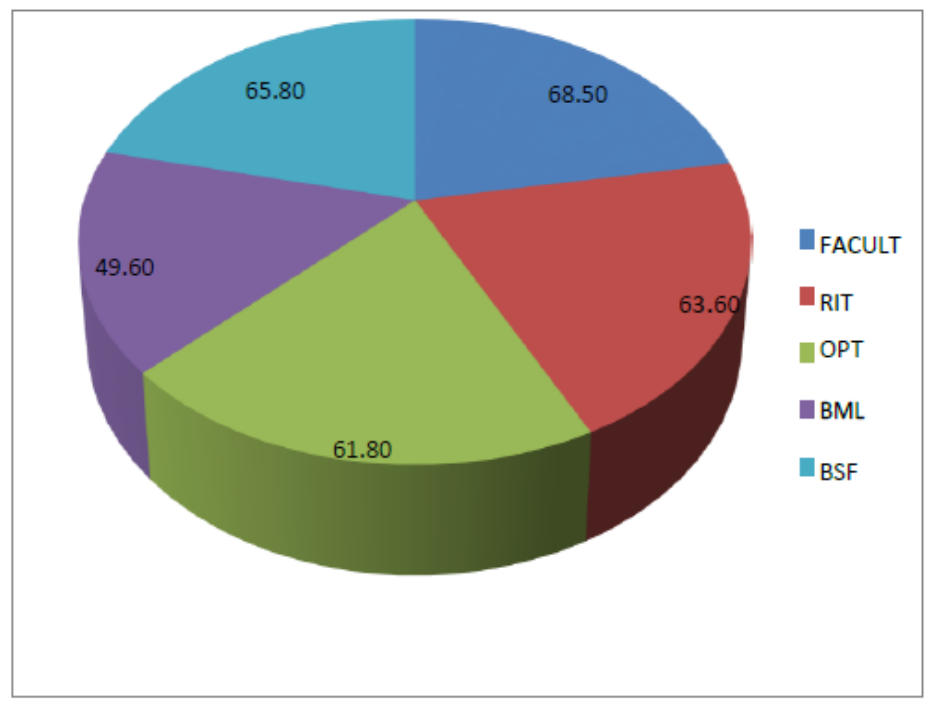

Pie chart shows the mean value of respondents

\section{DISCUSSION}

Fawzia Habib, et al has been conducted their study Awareness and Knowledge of Breast Cancer among University Students in Al Madina Al Munawara Region and concluded that this investigation uncovered that respondents showed inadequate information about central points of contention concerning breast malignant growth and its initial identification measures. It additionally uncovered that wellbeing laborers were not the principle wellspring of data locally, along these lines representing a test for local 
Fauzia Khan et.al. Assessment of knowledge of breast cancer risk factors and practice of breast self examination among paramedical females.

area wellbeing administrations to give fundamental required data about breast disease.

In this study assess the knowledge of female faculty and students about Breast cancer, risk factors and practice of Breast Self Examination and calculated the mean value of respondents who give the correct answer and concluded that the knowledge of female faculty had average $63.08 \%$, Radiology and Imaging Techniques students had good knowledge $63.6 \%$, Optometry students had insufficient knowledge $61.88 \%$, Bachelor of Medical Laboratory Techniques had insufficient knowledge $49.63 \%$ and Bachelor of Forensic Sciences were average knowledge $65.8 \% . \%$.The result of this study was not satisfied,

Knowledge of respondents was not enough for this serious and most common cancer of women.

\begin{tabular}{|c|c|}
\hline Total Result & Mean values \\
\hline FACULTY & 63.08 \\
\hline RIT & 63.6 \\
\hline OPT & 61.88 \\
\hline BMLT & 49.63 \\
\hline BFS & 65.8 \\
\hline
\end{tabular}

\section{CONCLUSION}

Study concluded that there should be proper lectures and theory classes for the conduction of knowledge about Breast cancer, risk factors and BSE in paramedical college. Demonstration of BSE and teaching standards should be taken in account for not only the number of hours required to obtain the knowledge with the equipment required to run the classes in the simulation-based learning environment. This questionnaire based survey demonstrate that up-to-date practice of breast self examination among paramedical females were not sufficient, this should be improved by the well designed training and theoretical sessions. From this study, we suggest that all members of the health care community should attend the webinars, guest lectures and training sessions about knowledge of breast cancer, risk factor and practice of breast self-examination.

\section{Acknowledgement: None}

Conflict of Interest: None

Source of Funding: None

Ethical Approval: Approved

\section{REFERENCES}

1. Habib, F, Salman, S., Safwat, M., \& Shalaby, S. (2010). Awareness and knowledge of breast cancer among university students in Al Madina Al Munawara Region.

2. Jay R.Harris, Marc E Lippman, Monica Morrow, C Kent or borne.(2010) The Diseases of the Breast.

3. P.R Ashalata, (2011) textbook of anatomy and physiology for nurses.

4. K Thalayan. (2001)Basic Radiological Physics.

5. Dr.Bhushans N Lakhkar (2016) Radiological Procedures.

6. Radi, S. M. (2013). Breast cancer awareness among Saudi females in Jeddah. Asian Pacific Journal of Cancer Prevention, 14(7), 4307-4312.

7. Sambanje, M. N., \& Mafuvadze, B. (2012). Breast cancer knowledge and awareness among university students in Angola. Pan African Medical Journal, 11(1).

8. Yadav, P., \& Jaroli, D. P. (2010). Breast cancer: awareness and risk factors in college-going younger age group women in Rajasthan. Asian Pac J Cancer Prev, 11(2), 319-22.

9. Boulos, D. N., \& Ghali, R. R. (2014). Awareness of breast cancer among female students at Ain Shams University, Egypt. Global journal of health science, 6(1), 154.

10. Boulos, D. N., \& Ghali, R. R. (2014). Awareness of breast cancer among female students at Ain Shams University,

11. Somdatta, P., \& Baridalyne, N. (2008). Awareness of breast cancer in women of an urban resettlement colony. Indian journal of cancer, 45(4), 149 
Fauzia Khan et.al. Assessment of knowledge of breast cancer risk factors and practice of breast self examination among paramedical females.

12. Abdel Hadi, M. S. (2000). Breast cancer awareness among health professionals. Annals of Saudi medicine, 20(2), 135136.

13. Alam, A. A. (2006). Knowledge of breast cancer and its risk and protective factors among women in Riyadh. Annals of Saudi medicine, 26(4), 272-277.

14. Jatoi, I. (2003). Screening clinical breast examination. The Surgical clinics of North America, 83(4), 789-801.
15. Wilson, C. M., Tobin, S., \& Young, R. C. (2004). The exploding worldwide cancer burden. International Journal of Gynecologic Cancer, 14(1).

How to cite this article: Khan F, Boora N, Kumar R et.al. Assessment of knowledge of breast cancer risk factors and practice of breast self examination among paramedical females. International Journal of Science \& Healthcare Research. 2021; 6(2): 312-317. DOI: https://doi.org/10.52403/ijshr.20210456 